\title{
Rapid and quantitative detection of C-reactive protein based on quantum dots and immunofiltration assay
}

This article was published in the following Dove Press journal:

International Journal of Nanomedicine

30 September 2015

Number of times this article has been viewed

\author{
Pengfei Zhangl,* \\ Yan Bao',* \\ Mohamed Shehata Draz ${ }^{2,3, *}$ \\ Huiqi Lu' \\ Chang Liu' \\ Huanxing Han' \\ 'Center for Translational Medicine, \\ Changzheng Hospital, Second \\ Military Medical University, Shanghai, \\ People's Republic of China; ${ }^{2}$ Zhejiang- \\ California International Nanosystems \\ Institute, Zhejiang University, \\ Hangzhou, Zhejiang, People's Republic \\ of China; ${ }^{3}$ Faculty of Science, Tanta \\ University, Tanta, Egypt \\ *These authors contributed equally \\ to this work
}

Correspondence: Pengfei Zhang;

Huanxing Han

Center for Translational Medicine,

Changzheng Hospital, Second Military

Medical University, 800 Xiangyin Road,

Shanghai 200003, People's Republic

of China

Tel +86 2I 8187 1908

Email pfzhang2014@I63.com;

hanhuanxing@sohu.com

\begin{abstract}
Convenient and rapid immunofiltration assays (IFAs) enable on-site "yes" or "no" determination of disease markers. However, traditional IFAs are commonly qualitative or semiquantitative and are very limited for the efficient testing of samples in field diagnostics. Here, we overcome these limitations by developing a quantum dots (QDs)-based fluorescent IFA for the quantitative detection of C-reactive proteins (CRP). CRP, the well-known diagnostic marker for acute viral and bacterial infections, was used as a model analyte to demonstrate performance and sensitivity of our developed QDs-based IFA. QDs capped with both polyethylene glycol (PEG) and glutathione were used as fluorescent labels for our IFAs. The presence of the surface PEG layer, which reduced the non-specific protein interactions, in conjunction with the inherent optical properties of QDs, resulted in lower background signal, increased sensitivity, and ability to detect CRP down to $0.79 \mathrm{mg} / \mathrm{L}$ with only $5 \mu \mathrm{L}$ serum sample. In addition, the developed assay is simple, fast and can quantitatively detect CRP with a detection limit up to $200 \mathrm{mg} / \mathrm{L}$. Clinical test results of our QD-based IFA are well correlated with the traditional latex enhance immune-agglutination aggregation. The proposed QD-based fluorescent IFA is very promising, and potentially will be adopted for multiplexed immunoassay and in field point-of-care test.
\end{abstract}

Keywords: C-reactive proteins, point-of-care test, Glutathione capped QDs, PEGylation

\section{Introduction}

Serum C-reactive protein (CRP) is a routinely used biomarker for clinical detection of inflammation and rapid discrimination between bacterial and viral infections in humans. ${ }^{1-3}$ The normal concentration of CRP in the serum of a healthy human is usually lower than $10 \mathrm{mg} / \mathrm{L}$, while higher levels of CRP are usually related to different health conditions. CRP levels increase to $10-40 \mathrm{mg} / \mathrm{L}$ with the incidence of viral infections and mild inflammation, $40-200 \mathrm{mg} / \mathrm{L}$ with the incidence of bacterial infection and active inflammation, and $>200 \mathrm{mg} / \mathrm{L}$ with the incidence of severe bacterial infections and burns. ${ }^{2}$

Recent clinical research revealed that increased CRP levels, even within the range previously considered normal, strongly predict future coronary events. ${ }^{1,4,5}$ The American Heart Association and US Centers for Disease Control and Prevention ${ }^{6}$ have associated CRP levels over $1.0 \mathrm{mg} / \mathrm{L}$ with an increased risk of cardiovascular disease. However, conventional CRP detection methods for the clinical diagnosis of acute inflammation are not sensitive enough to detect cardiovascular risks according to this criteria. To measure the trace amount of CRP with high sensitivity, previous studies have reported using magnetic immunoassays with detection limits as low as $0.12 \mu \mathrm{g} / \mathrm{mL}^{7,8}$ Fluorescent immunosorbent assays were also developed for sensitive 
detection of CRP. ${ }^{9,10}$ Although, previous papers have reported success with the sensing system, these methods are usually time-consuming and complicated detection procedures. ${ }^{9,10}$

Immunofiltration assays (IFAs) generally rely on the liquid flow technology in which a porous nitrocellulose (NC) membrane is employed as a solid support for immobilizing or capturing the analyte to be detected, along with a proper signal reporting system in a typical sandwich reaction. ${ }^{1-13}$ Practically, IFAs are very simple, fast, and cost-effective. They are easy to use and do not require highly trained technicians nor expensive materials or equipment. ${ }^{14}$ Therefore, IFA applications are continuing to increase at a rapid pace especially in point-of-care testing and field diagnostics. ${ }^{15,16}$

However, traditional IFAs, especially those based on enzymes ${ }^{17}$ and gold nanoparticles, are preliminary qualitative or semi-quantitative and too limited for analyzing high concentrations of analytes. The major reasons for this limitation include the dependence of IFAs on label accumulation to generate detectable signals, non-specific bindings, and cross reactivity effects which commonly occur at a high protein concentration. ${ }^{18-20}$ Therefore, labeling reagents that possess stable and intense fluorescent signals are favored for achieving efficient and sensitive IFA detections. ${ }^{21}$ In this context, various types of labels were recently proposed to advance traditional IFAs, including colored latex, ${ }^{12,22}$ magnetic particles, ${ }^{23,24}$ gold nanoparticles, ${ }^{25,26}$ up-converting phosphors, ${ }^{27,28}$ and quantum dots (QDs). ${ }^{29,30}$ Among them, QDs are one of the most prominent candidates due to their high fluorescence quantum yield (QY), broad excitation, and size-dependent emission tunability, as well as excellent photostability. ${ }^{31,32}$ Currently, QDs have been promoted as ideal fluorescent labels for developing highly sensitive and multiplex immunoassays, ${ }^{33-36}$ yet QDs labels have not gained acceptance into standard clinical practice and their potential is largely limited due to either physical or chemical instability in biological solutions and media.

Herein, we developed, for the first time, a sandwich type IFA using polyethylene glycol (PEG)ylated QDs as labels for rapid and quantitative detection of CRP in human serum. QDs coated with both glutathione (GSH) and PEG layers were employed to boost the chemical and photostability of QDs and to alleviate the non-specific interactions. Based on the high performance QDs, we developed a QDs-based IFA for quantitative and sensitive detection of the CRP marker in human serum. The test results can be obtained within 5 minutes using only $5 \mu \mathrm{L}$ serum samples in one step. These features of the assay are more suitable for the on-site disease detection in an emergency situation.

\section{Materials and methods Materials}

Cadmium oxide (CdO, 99.99\%), trioctylphosphine oxide (TOPO, 90\%), trioctylphosphine (TOP, 90\%), octadecylamine (ODA, 90\%), $N$-hydroxysuccinimide (NHS, 98\%), diisopropylcarbodiimide (DIC, 99\%), and bovine serum albumin (BSA) were purchased from Sigma-Aldrich Co. (St Louis, MO, USA) . Sulfo- $N$-hydroxysuccinimide (sulfo-NHS, 98.5\%) and 1-ethyl-3-(3-di-methylaminopropyl) carbodiimide hydrochloride (EDC, 99\%) were purchased from Thermo Fisher Scientific (Waltham, MA, USA). Selenium (Se, 99.99\%), stearic acid (SA, 99\%), sulfur powder (99.9\%), zinc oxide ( $\mathrm{ZnO}, 99 \%)$, oleic acid (OA, 99\%), liquid paraffin, and reduced GSH (90\%) were obtained from Sinopharm Chemical Reagent Co., Ltd (Shanghai, People's Republic of China). Carboxyl-PEG-carboxyl $\left(M_{\mathrm{n}}=2,000 \mathrm{Da}\right)$ was purchased from Jiaxing Biomatrix and Biotechnology Inc. (Jiaxing, People's Republic of China) Standard CRP and monoclonal mouse-anti-CRP antibody were provided by Shanghai Upper Bio-Tech Pharma Co., Ltd (Shanghai, People's Republic of China). CRP free serum obtained from HyTest Ltd (Turku, Finland) were used for preparation of standard CRP samples. All the reagents were used as they were received and without any further purification.

\section{Synthesis of QDs}

$\mathrm{CdSe} / \mathrm{ZnSe} / \mathrm{ZnS}$ core/shell/shell QDs were used for immunoassay because of their improved QYs and photostability when compared to $\mathrm{CdSe} / \mathrm{ZnS}$ core/shell QDs. ${ }^{37,38}$ The typical procedure of QDs synthesis follow. CdSe core were synthesized and coated with $\mathrm{ZnSe}$ and $\mathrm{ZnS}$ multi-shell according to the previously reported method. Briefly, CdSe cores were synthesized by heating a mixture of $1 \mathrm{mmoL} \mathrm{CdO}$ powder, $4 \mathrm{mmoL} \mathrm{SA}$, and $10 \mathrm{~mL}$ liquid paraffin. The mixture solution was degassed and heated to $200^{\circ} \mathrm{C}$ with magnetic stirring until $\mathrm{CdO}$ was completely dissolved. After cooling to room temperature, $1 \mathrm{~g}$ TOPO, $3 \mathrm{~g}$ ODA, and $10 \mathrm{~mL}$ liquid paraffin were added to the flask, heated to $280^{\circ} \mathrm{C}$ under nitrogen protection, and then $5 \mathrm{~mL}$ of $1 \mathrm{M} \mathrm{Se}$ in TOP was rapidly injected into the Cd-containing reaction mixture followed by cooling to room temperature after 30 minutes reaction at $260^{\circ} \mathrm{C}$.

For $\mathrm{ZnSe}-\mathrm{ZnS}$ shell coating process, CdSe cores isolated by repeated precipitations from chloroform with methanol, were heated to $220^{\circ} \mathrm{C}$ in a mixture of $5 \mathrm{~g}$ ODA and $15 \mathrm{~mL}$ liquid paraffin under nitrogen protection. Then, aliquots of $\mathrm{Zn}$ and $\mathrm{Se} / \mathrm{S}$ precursor solutions were alternately introduced starting with $\mathrm{Zn}$ precursor, waiting 20 minutes between each 
addition. After shell coating, QDs were annealed at $260^{\circ} \mathrm{C}$ for another 20 minutes, and then cooled to room temperature. Finally, core-shell QDs were isolated from the solution with chloroform and methanol via centrifugation, washed three times, and stored in chloroform.

\section{Surface modification of QDs}

In a typical procedure, $250 \mathrm{mg}$ of GSH and $200 \mathrm{mg}$ of sodium hydroxide were dissolved in $10 \mathrm{~mL}$ of methanol, and mixed with $5 \mathrm{~mL}$ of $10 \mu \mathrm{M}$ ODA-coated CdSe/ZnSe/ZnS QDs chloroform solution. Afterward, the solvents in the mixture were gradually evaporated with magnetic stirring under room temperature overnight, and then $25 \mathrm{~mL}$ of water was added to disperse the precipitates. Subsequently, $1 \mathrm{~mL}$ of $1 \mathrm{M} \mathrm{ZnCl}_{2}$ solution was added dropwise while stirring and heated to $60^{\circ} \mathrm{C}$ for 10 minutes to enhance the QYs. Then the QDs solution were filtered through a $0.22 \mu \mathrm{m}$ syringe filter to remove the aggregates, and dialyzed against pure water for 48 hours with a $14 \mathrm{kDa}$ molecular weight cutoff (MWCO) dialysis tubing to remove the excess of unbound GSH. Finally, GSH-QDs aqueous solution was concentrated to approximately $5 \mu \mathrm{M}$ by rotary evaporation under reduced pressure.

To improve the colloidal and chemical stability of QDs as in our previous report, ${ }^{39}$ PEGylated polymer caged QDs were prepared using carboxyl-PEG-carboxyl as crosslinkers. Typically, $5 \mu \mathrm{moL}$ of NHS and $5 \mu \mathrm{moL}$ of DIC were added into $10 \mu \mathrm{moL}$ of carboxyl-PEG-carboxyl in $5 \mathrm{~mL}$ dimethyl sulfoxide (DMSO) solution, and allowed to react for 30 minutes at room temperature to activate the carboxyl groups. Afterward, DTT was added into the solution to quench the excess DIC, and GSH-QDs were then added to the solution, and the reaction continued for another 4 hours. The resultant mixture was dialyzed against pure water for 48 hours to carefully remove the unbound PEG and other small molecules using a $14 \mathrm{kDa}$ MWCO dialysis tubing. The solution was then finally concentrated by rotary evaporation under reduced pressure. During the course of our study, different ratios of DIC, NHS, PEG, and QDs were used to obtain optimal methodologies.

\section{Preparation of QD-antibody conjugates}

The covalent conjugation of antibody onto QDs was achieved through using the classic strategy of EDC coupling reaction between the carboxyl groups on the surface of QDs and the amino groups in the antibodies. Typically, $100 \mu \mathrm{L}$ of QDs $(5.0 \mu \mathrm{M})$ was dispersed in $200 \mu \mathrm{L}$ phosphate-buffered saline (PBS) buffer (10 mM, pH 6.0) in a tube. Sulfo-NHS $(500 \mathrm{nmoL})$ and $\mathrm{EDC}(500 \mathrm{nmoL})$ were added and incubated for 30 minutes at room temperature to activate the carboxyl groups. Over excess activators were removed by centrifugation at 20,000 rpm for 0.5 hour and carefully removing the supernatant. T resultant pellet was dispersed in $500 \mu \mathrm{L}$ of borate buffer (10 mM, pH 8.0). Following this, anti-CRP labeling antibodies $(120 \mu \mathrm{g})$ were added into activated QDs and the mixture was incubated at room temperature for 2 hours. In order to block unreacted carboxyl groups on the surface of QDs, BSA $(0.5 \mathrm{mg})$ was added into the tube, and incubated for another 30 minutes. The mixture was purified by ultracentrifugation at 20,000 rpm for 1 hour, and then washed twice with PBST buffer (PBS with $0.05 \%$ Tween $^{\circledR} 20$ ) to remove free antibodies and other unreacted small molecules. The purified QD-antibody conjugates were finally dispersed in PBS buffer and stored at $4^{\circ} \mathrm{C}$.

\section{Characterization of the prepared QDs and QDs-antibody conjugates}

Absorption $(\mathrm{Ab})$ spectra were acquired with an ultravioletvisible (UV-Vis) spectrophotometer (Shimadzu 2450; Shimadzu Corporation, Kyoto, Japan), and fluorescent spectra were recorded on a fluorescence spectrometer (PerkinElmer Inc., Waltham, MA, USA). The morphology and size of QDs were analyzed with a transmission electron microscope (TEM; Hitachi-7650, Hitachi Ltd, Tokyo, Japan) at an accelerating voltage of $100 \mathrm{kV}$. The hydrodynamic diameters and size distribution of QDs were determined by a NICOMPTM ZLS system (Particle Sizing Systems, Port Richey, FL, USA). The particle size distribution analysis was conducted by the NICOMP number-weighted distribution analysis.

\section{Immunofiltration assay}

QDs-based immunoassay was performed using an immunofiltration system. The system was mainly composed of a thin, porous NC membrane on which CRP monoclonal antibody was immobilized. The membrane was positioned over an absorbent paper and sealed in a plastic cassette containing a hole to expose the membrane. The sample was firstly mixed with QD-antibody conjugates, and antigens in the sample were to be captured by QD-antibody conjugates. Subsequently, the assay was typically performed as following: First, $5 \mu \mathrm{L}$ of the serum sample was added into the QD-antibody conjugates solution and gently pipetted for a minimum of three times. Second, $120 \mu \mathrm{L}$ of conjugates solution was added into the hole of immunofiltration device. After the conjugates solution totally soaked in, $200 \mu \mathrm{L}$ of washing buffer was added to rinse the unbound conjugates. The whole assay can be finished within 5 minutes. The test 
results could be read by naked eye under UV light (365 nm) illumination, and the corresponding fluorescent images were captured directly by a Canon digital camera (G12; Canon Inc., Tokyo, Japan). The fluorescent intensities of QDs on test spots were measured by an optical fiber spectroscopy couple with a UV laser (405 nm).

\section{Clinical samples}

A total of 50 human serum samples from 43 patients with chronic hepatitis B virus (HBV), and seven patients with hepatitis $\mathrm{C}$ virus infections were obtained from Shanghai Changzheng Hospital. All clinical samples were firstly analyzed and the levels of CRP were measured using a commercial latex agglutination kit (Shanghai Kehua Medical Instruments Co., Ltd, Shanghai, People's Republic of China), along with our developed QDs-based IFA. The study and data analyses were approved by the Ethics Committee of Shanghai Changzheng Hospital. Patient consent was not obtained as all personal identifiers and patient information were delinked from the serum specimens.

\section{Results}

\section{Assembly and working principle of the QDs-immunofiltration assay}

The developed fluorescent QD-IFA was used for sensitive and rapid detection of the CRP marker. It is mainly comprised of a porous NC membrane modified with CRP-capturing antibody and an absorbent pad assembled in a plastic cassette (Figure 1A); the working principle is schematically shown in Figure 1B. The serum sample is firstly added to the labeling QDs- antibody conjugates. When CRP is present in the sample, it specifically interacts

A

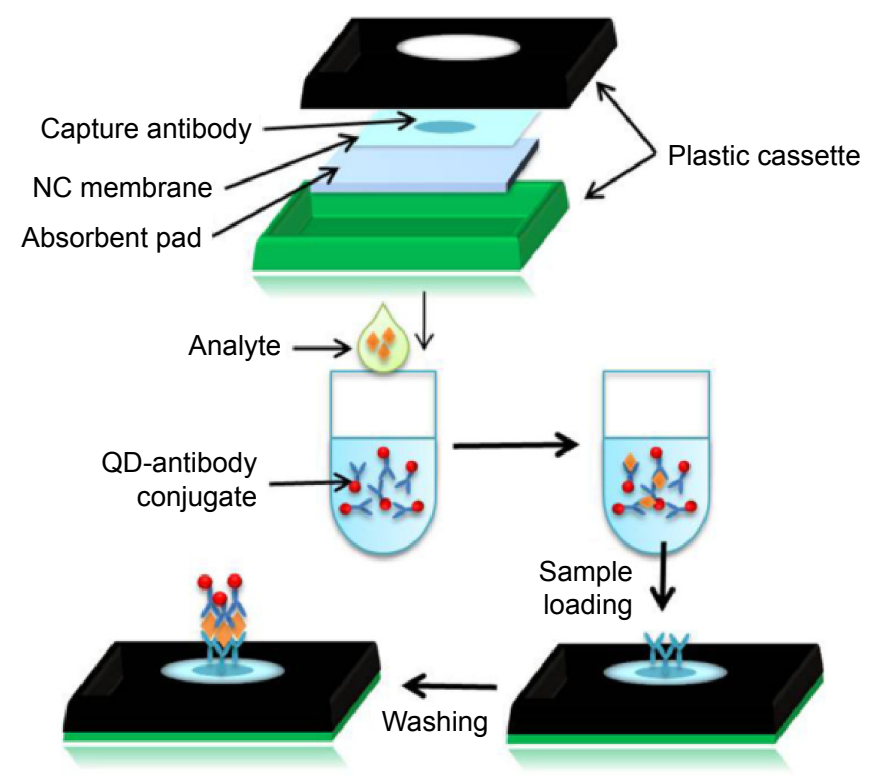

C

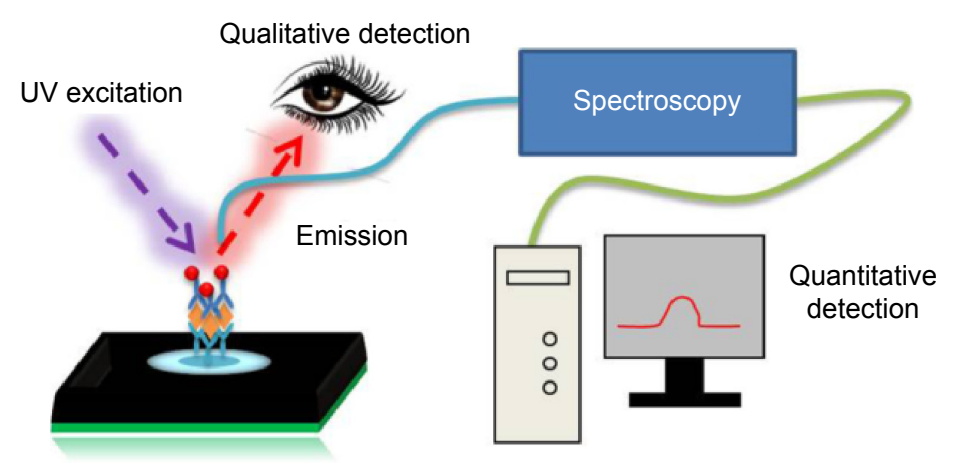

Figure I Schematic illustration of the PEGylated QDs-based immunofiltration assay.

Notes: (A) The structure illustration of the immunofiltration pad. (B) The detection process includes an initial step of serum sample mixing with QD-antibody conjugate followed by sample loading and washing with buffer. (C) The qualitative detection is monitored by naked eye under UV light illumination, while the quantitative detection of the resulted fluorescent signals is carried out using an optical fiber spectroscopy and $405 \mathrm{~nm}$ laser excitation.

Abbreviations: QD, quantum dot; UV, ultraviolet; NC, nitrocellulose; PEG, polyethylene glycol. 
with the labeling conjugates. The formed complex is then specifically captured by antibodies previously immobilized on the NC membrane. After a simple washing step and under UV light illumination, the formed three-component sandwich immunocomplexes can be directly visualized by the naked eye for qualitative detection of CRP or quantitatively measured using an optical fiber spectroscopy (Figure 1C). The measured fluorescence intensity was observed to significantly increase with the gradual accumulation of QD conjugates on the antibody spot indicating the potentiality of the developed QD-IFA assay for accurate quantitative detection of CRP.

\section{Characterization of the prepared QDs and QD-antibody conjugates}

High quality multi-shell CdSe/ZnSe/ZnS QDs coated with ODA/TOPO were synthesized for the preparation of labeling probes. Hydrophobic QDs with a QY over 50\% were solubilized in water by replacing the ODA/TOPO ligands from their surface with GSH. ${ }^{39,40}$ The obtained water-soluble QDs displayed a high QY around 30\% and an ultra-small hydrodynamic diameter of less than $10 \mathrm{~nm}$ (Figures S1 to S4). PEG derivatives with terminal $\mathrm{COOH}$ groups were grafted on the surface of GSH-QDs with controlled ratio (Figure 2A). ${ }^{39}$ Identical absorbance
A

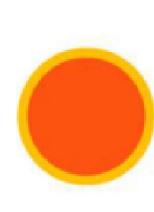

GSH-QDs

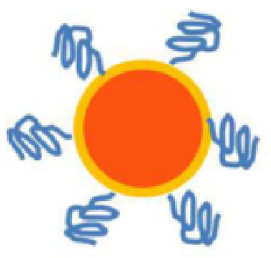

PEG/GSH-QDS

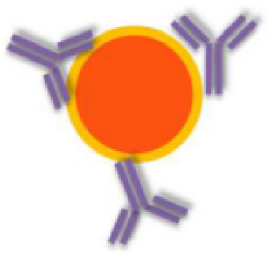

GSH-QDs-Ab

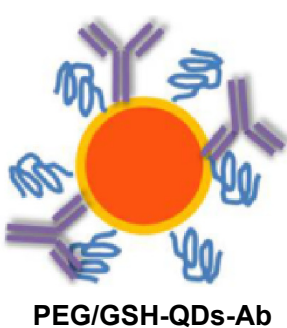

PEG/GSH-QDS-Ab

B

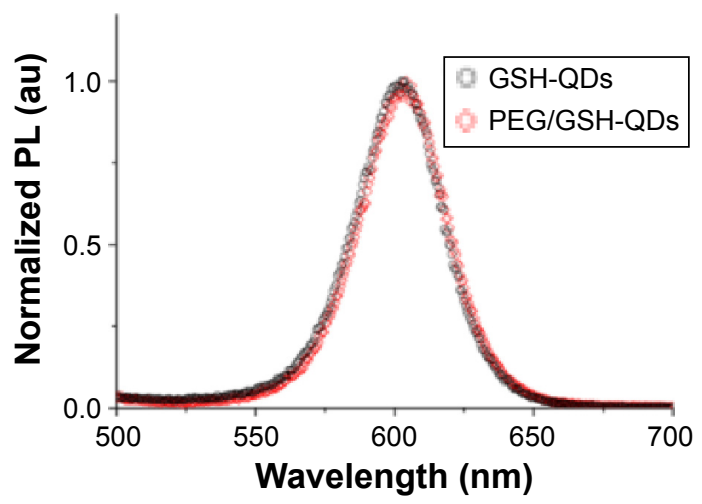

C

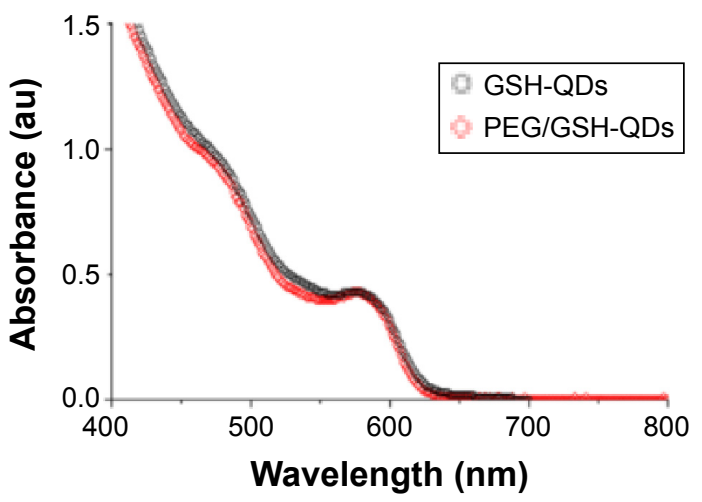

D

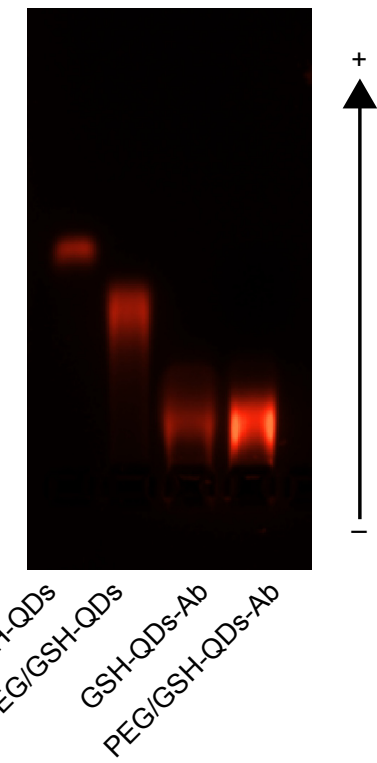

Figure 2 Synthesis and characterization of PEGylated QDs and QD-antibody conjugates.

Notes: (A) Schematic of QD and QD-antibody structure applied for CRP detection using IFA system. Identical fluorescence emission (B) and UV-Vis absorbance (C) spectra of GSH-QDs (black circle) and PEGylated GSH-QDs (red rhombus) dissolved in PBS buffer solution (0.0I M, pH 7.2). (D) Agarose gel electrophoresis of QDs and QD-antibody conjugates, running at $80 \mathrm{~V}$ for 20 minutes.

Abbreviations: Ab, antibody; QD, quantum dot; UV-Vis, ultraviolet-visible; IFA, immunofiltration assay; CRP, C-reactive protein; GSH, glutathione; PEG, polyethylene glycol; PL, photoluminescence; PBS, phosphate-buffered saline. 


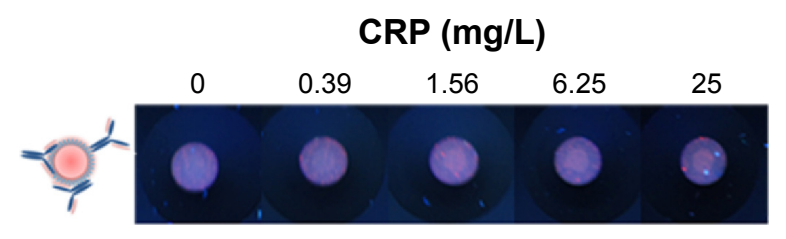

GSH-QDs

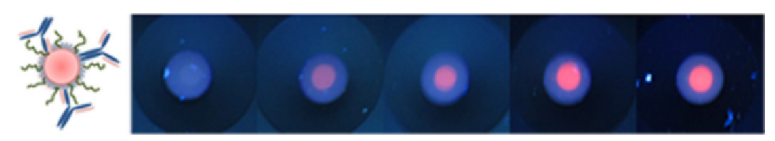

PEG/GSH-QDs

Figure 3 Comparative detection of CRP using QDs labeling conjugates prepared from GSH-QDs and PEG/GSH-QDs conjugates.

Note: $5 \mu \mathrm{L}$ of standard CRP sample in serum added to $200 \mu \mathrm{L}$ of $20 \mathrm{nM}$ QD conjugates solution, then $I 20 \mu \mathrm{L}$ aliquot was loaded into IFA pad.

Abbreviations: QD, quantum dot; IFA, immunofiltration assay; CRP, C-reactive protein; GSH, glutathione; PEG, polyethylene glycol.

and fluorescent spectra of GSH-QDs and PEG/GSH-QDs indicate that PEG modification have minor influence on the optical properties of QDs (Figure 2B and C). While in agarose gel electrophoresis, the migration rate of PEG/GSH-QDs is decreased due to the PEG derivative conjugation on GSH-QDs (Figure 2D). In addition, the obtained colloidal solution of PEG/GSH-QDs remained stable in the $\mathrm{pH}$ buffer and crosslinker chemical solution, and displayed a compact hydrodynamic diameter of $15.1 \pm 2.1 \mathrm{~nm}$ (Figure S4).

CRP-specific monoclonal antibodies were coupled with the surface PEG layer of QDs via carboxyl and amine groups using carbodiimide chemistry. Successful conjugation of antibodies was evidenced using the agarose gel electrophoresis technique (Figure 2D). The addition of CRP antibody with large molecular weight and slightly positive charge resulted in hindered QD-antibody conjugate migration in gel electrophoresis.

\section{Effect of QDs PEGylation on the performance of QDs-immunofiltration assay}

The immunoassay performance of QD conjugates obtained from GSH-QDs and PEG/GSH-QDs was compared to elucidate the effect of PEG layer on the performance of IFA. Fluorescent images of IFA pads tested using GSHQDs and PEG/GSH-QDs are presented in Figure 3. There was a strong non-specific binding between QDs conjugates made of GSH-QDs when compared with that made of PEG/ GSH-QDs. As shown in Figure S5, this non-specific binding was obvious even though there was no capturing antibody immobilized on the surface of NC membrane. Whereas, the addition of PEG to QDs helped largely to suppress most of the non-specific interactions in the tested CRP concentration range of $0-25 \mathrm{mg} / \mathrm{L}$. Moreover, immunoassays using PEG/ GSH-QDs conjugates are more sensitive and have reliable test results.

\section{Optimization of experimental conditions}

In addition to QDs surface chemistry, many other factors are expected to influence the detection sensitivity and dynamic range of the developed assay, including the concentration of the QD-antibody probe, the dilution of the target sample, and these factors need to be optimized. The influence of
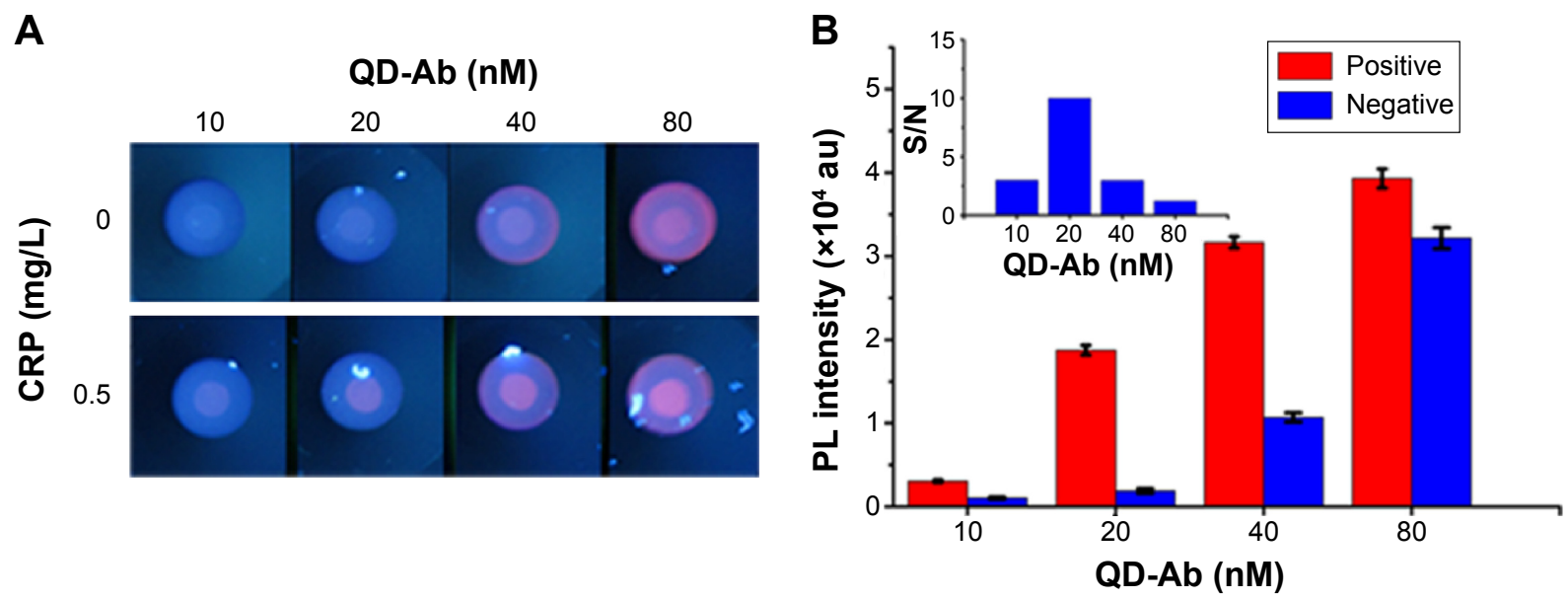

Figure 4 Optimization of the detection conditions for PEGylated QDs-based immunofiltration assay for CRP.

Notes: Typical images $(\mathbf{A})$ and quantitative fluorescent response $(\mathbf{B})$ of QDs-base immunofiltration assay for negative $(0 \mathrm{mg} / \mathrm{L})$ and positive $(0.5 \mathrm{mg} / \mathrm{L}) \mathrm{CRP}$ samples in serum using different concentrations of QDs conjugates. The inset figure in (B) shows the signal/noise (S/N) ratio calculated from the PL intensity ratio of positive to negative samples under different concentrations of the QDs conjugates. ( $5 \mu \mathrm{L}$ of CRP samples in serum added to $200 \mu \mathrm{L}$ of different concentration of QD conjugates solution, then I $20 \mu \mathrm{L}$ aliquot was loaded into IFA pad.)

Abbreviations: QD, quantum dot; Ab, antibody; IFA, immunofiltration assay; CRP, C-reactive protein; PEG, polyethylene glycol; PL, photoluminescence. 
QD conjugate concentrations on the assay performance was investigated. Different concentrations of QD conjugates were tested for detection along with both negative and positive control samples. As shown in Figure 4, both fluorescent images and quantitative test results indicated that high concentrations of QD conjugates ( $\geq 40 \mathrm{nM}$ ) resulted in an intense background fluorescence signals. In contrast, concentrations of QD probes that are too low can eventually reduce the fluorescent signal responses as observed on the antibody spot tested with positive samples. Therefore, the signal/noise $(\mathrm{S} / \mathrm{N})$ ratio was calculated and optimized based on the fluorescence intensity ratio of positive to negative samples. As shown in the lower inset of Figure 4B, the optimum $\mathrm{S} / \mathrm{N}$ ratio can be achieved when the concentration of QD conjugates is approximately $20 \mathrm{nM}$.

Our test is an immunoassay and its dynamic range of detection is largely expected to be affected by the dilution of original samples. We evaluated the dynamics of the assay and the extent of high-dose hook effect ${ }^{41}$ using different dilutions of samples. For this part of the process, $5 \mu \mathrm{L}$ of serum samples were diluted to 81 - and 161-fold using $400 \mu \mathrm{L}$ and $800 \mu \mathrm{L}$ of QD conjugates, respectively, and $120 \mu \mathrm{L}$ aliquot was loaded on the IFA pad for detection (Figure 5). As shown in Figure 6, the dynamic range of the assay was extend from 1.0 to $200 \mathrm{mg} / \mathrm{L}$ with 161 -fold dilution of serum samples.
At the same time, the sensitivity of the assay was also slightly reduced because of the increased dilution of samples in the QD conjugate solution. According to clinical reference concentration range of CRP in serum $(0.5-200 \mathrm{mg} / \mathrm{L})$, we selected $800 \mu \mathrm{L}$ of QD conjugate for further analysis.

\section{The analytical performance and sensitivity of QDs-immunofiltration assay}

Under optimal experimental conditions, the analytical performance of the assay was evaluated with standard CRP samples. Each sample was measured in triplicate and the average results are shown in Figure 7A and B. For the qualitative detection of CRP, Figure 7A displays the fluorescent images of the testing spot on the immunofiltration pad after the performance of assay. The results can be clearly and easily observed with the naked eye under UV lamp illumination. This is mainly owing to the high fluorescence intensity and photostability of QDs. Also, the ascending increase in the concentration of CRP causes more QD conjugates to be captured on the test spot and directly intensifies the fluorescence signals generated from the test spot. Interestingly, the fluorescence intensity of the test spot in the negative CRP samples is very weak and can be easily distinguished from the positive sample even at very low CRP concentration of $0.19 \mathrm{mg} / \mathrm{L}$, which can be considered as
A
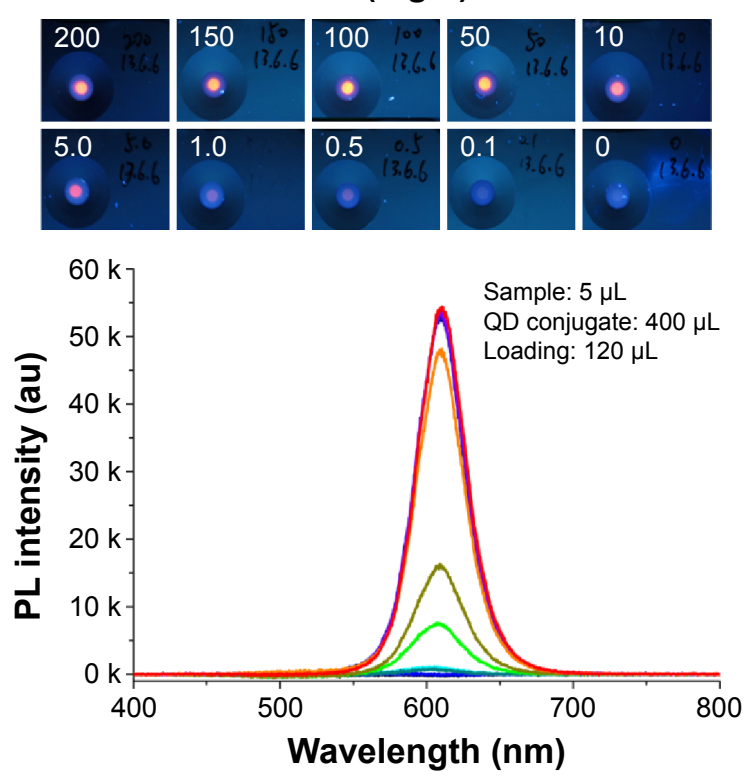

B
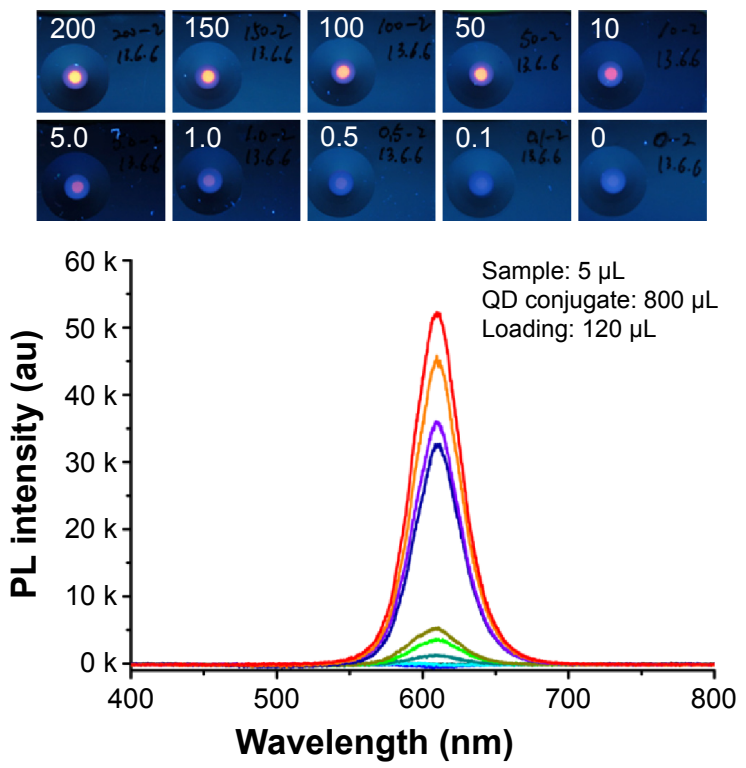

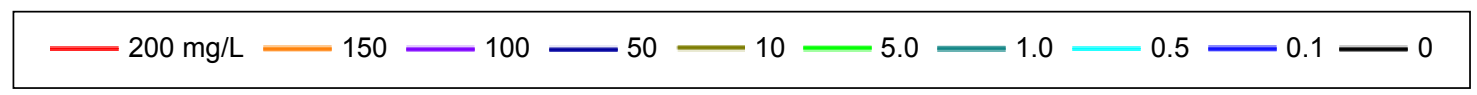

Figure 5 Fluorescent images (upper) and spectra (lower) of immunofiltration pad spot tested with a series of CRP samples.

Notes: $5 \mu \mathrm{L}$ of CRP samples in serum respectively added to $400 \mu \mathrm{L}(\mathbf{A})$ and $800 \mu \mathrm{L}$ (B) of $20 \mathrm{nM}$ QD conjugates solution, then I20 $\mu \mathrm{L}$ aliquot was loaded into IFA pad. Abbreviations: QD, quantum dot; IFA, immunofiltration assay; CRP, C-reactive protein; PL, photoluminescence. 


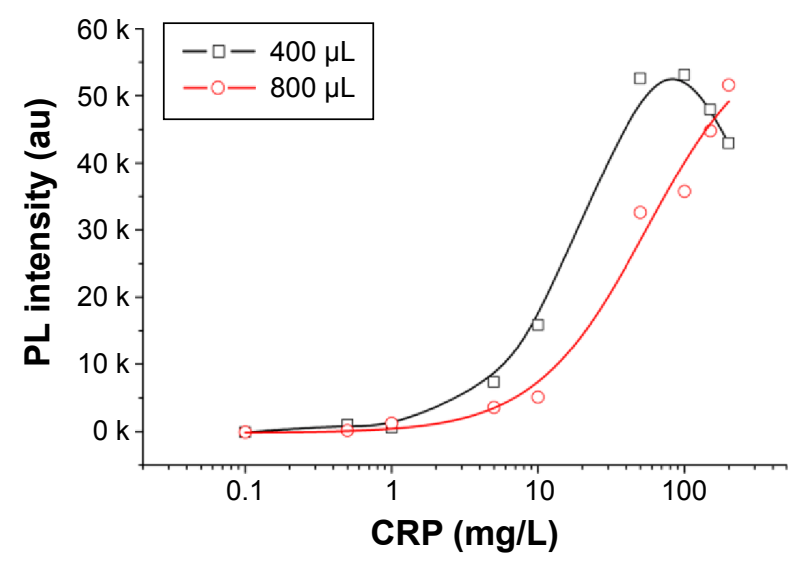

Figure 6 The quantitative dynamic range of the developed QDs-based immunofiltration assay using different volume of QDs conjugates.

Abbreviations: $\mathrm{QD}$, quantum dot; $\mathrm{CRP}$, C-reactive protein; $\mathrm{PL}$, photoluminescence.

the limit of detection (LOD) for visual qualitative detection using our assay. On the other hand, the test results were also quantified by an optical fiber spectroscopy under excitation with a $405 \mathrm{~nm}$ laser. The standard curve for this QDs-based IFA was constructed by drawing the values of fluorescence spectra peak area against the concentration of CRP (Figure 7B). From this figure, the LOD of our assay using fiber spectroscopy can be $0.79 \mathrm{mg} / \mathrm{L}$, when LOD is defined as the concentration corresponding to a signal that is 3 times SD (standard deviation) above the negative samples. The total results are cumulatively confirming that the developed test can be potentially considered for the rapid qualitative and quantitative testing of CRP serum samples in 5 minutes, depending on the conditions and requirements.

\section{Application of QDs-immunofiltration assay for detecting CRP in human serum}

Finally, 50 clinical serum samples were collected to evaluate the developed method for field detection of CRP in human serum. All samples were parallel tested by a standard assay of CRP using a commercial latex agglutination kit, and our optimized QDs-IFA. Linear regression analysis revealed good correlation between our proposed method and this widely used commercial immunoassay kit. The equation of the regression curve was $y=0.9169 x+2.3095$, and correlation coefficient was $r=0.9805$, which implied that our QD-base assay can be applied for clinical determination of CRP in human serum.

\section{Discussion}

CRP is known to be synthesized by the liver and frequently secreted into plasma in response to different levels of inflammations, various types of microbial infections, and cancer. ${ }^{42,43}$ The change of CRP concentration in blood serum is frequently correlated to different health conditions. Thus, CRP is currently gaining more importance as a differential

A

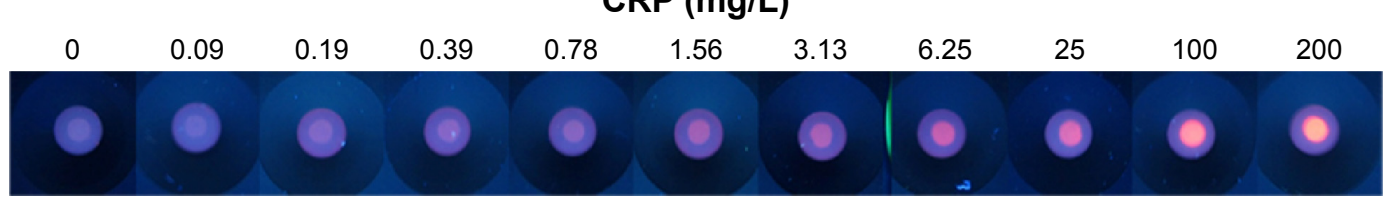
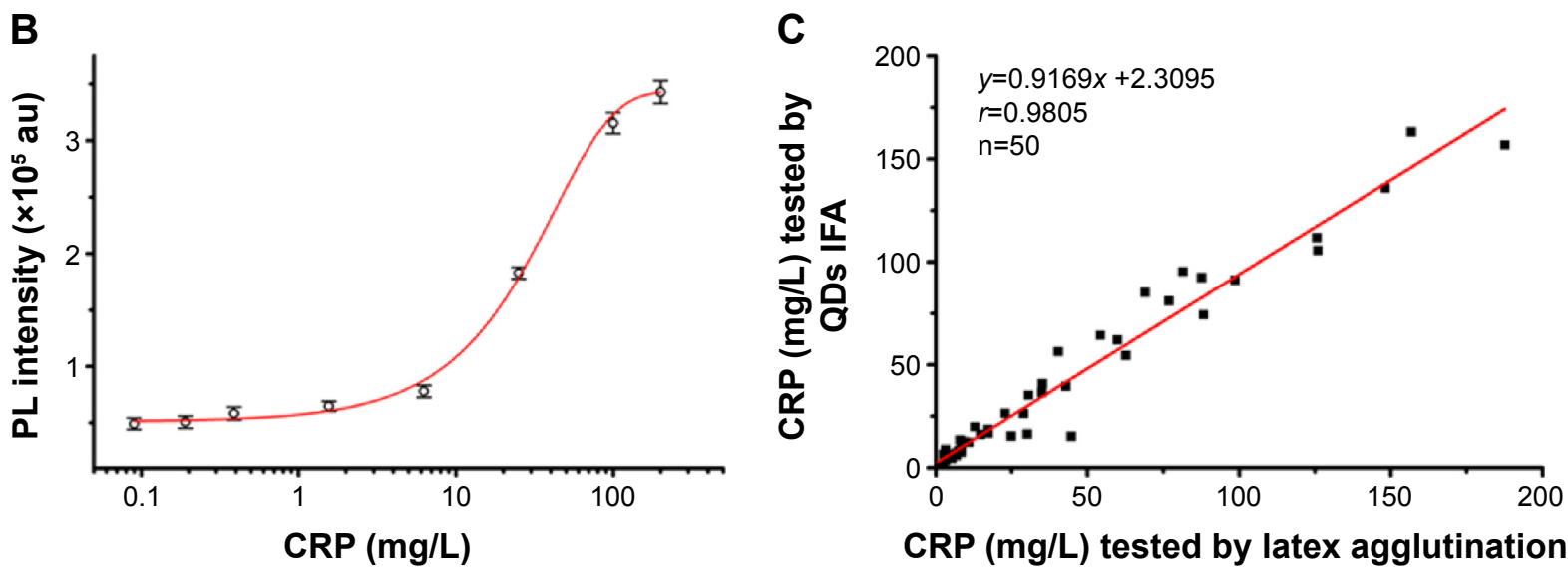

Figure 7 Application of the developed QD-based immunofiltration assay for CRP detection.

Notes: (A) Typical fluorescent images of detection results carried out with twofold serially diluted CRP calibrator and a negative control (0 mg/L CRP serum sample) $5 \mu \mathrm{L}$ of CRP samples in serum respectively added to $800 \mu \mathrm{L}$ of $20 \mathrm{nM}$ QD conjugates solution, then $120 \mu \mathrm{L}$ aliquot was loaded into IFA pad. (B) The calibration curve of the quantitative detection by the developed QD-based immunofiltration assay. (C) Correlation between the results of QD-based immunofiltration assay and latex enhanced immune-agglutination assay for 50 human serum samples.

Abbreviations: QD, quantum dot; IFA, immunofiltration assay; CRP, C-reactive protein; PL, photoluminescence. 
Table I Comparison of developed QD-based IFA with other QDs-based assays and traditional ELISA methods for CRP detection

\begin{tabular}{llllll}
\hline Methods & $\begin{array}{l}\text { QD-based } \\
\text { IFA }\end{array}$ & $\begin{array}{l}\text { QD-based lateral } \\
\text { flow immunoassay }\end{array}$ & $\begin{array}{l}\text { QD labeled microplate } \\
\text { immunoassay }\end{array}$ & $\begin{array}{l}\text { QD labeled magnetic } \\
\text { beads immunoassay }\end{array}$ & $\begin{array}{l}\text { Traditional } \\
\text { ELISA }^{\text {(0) }}\end{array}$ \\
\hline Detection limit & $0.79 \mathrm{mg} / \mathrm{L}$ & $0.25 \mathrm{mg} / \mathrm{L}$ & $0.06 \mu \mathrm{g} / \mathrm{L}$ & $\mathrm{I} \mu \mathrm{g} / \mathrm{L}$ & $0.16 \mathrm{mg} / \mathrm{L}$ \\
Detection time & $<5$ minutes & 15 minutes & $1-1.5$ hours & $1 \sim 3$ hours & Over 12 hours \\
Sample required & $5 \mu \mathrm{L}$ & $10 \mu \mathrm{L}$ & $100 \mu \mathrm{L}$ & $50-100 \mu \mathrm{L}$ & $5 \mu \mathrm{L}$ \\
Test procedure & One step & One step & Two steps & Three steps & Three steps \\
\hline
\end{tabular}

Abbreviations: QD, quantum dot; IFA, immunofiltration assay; CRP, C-reactive protein; ELISA, enzyme-linked immunosorbent assay.

biomarker in clinical diagnosis. However, this potential is not yet fully realized in field applications, mainly due to the absence of efficient and sensitive assays for the quantitative in field detection of CRP.

We have demonstrated quantitative and sensitive detection of CRP in serum using QD-antibody conjugates based IFA. Following our glutathione and PEG coating approach, the prepared QD-antibody conjugates have negligible nonspecific binding and high stability against aggregation ${ }^{39}$ which are especially favorable for quantitative protein detection using IFAs.

It is possible to envision that the non-specific binding in IFAs is mainly caused by the hydrophobic and electrostatic interactions taking place between the loaded QD-antibody conjugates and NC membrane. Surface modification of QDs with PEG can shield the negative charge of both the core QD nanocrystals and loaded antibodies. ${ }^{44,45}$ This will directly change the electrical double layer surrounding the QDs and increase the total hydrophilicity of QDs-antibody labeling conjugates. This will subsequently reduce the possibility of hydrophobic and electrostatic binding of labeling conjugates with $\mathrm{NC}$ membrane, allowing lower background signal and better detection performance and sensitivity. This was further confirmed by studying the effect of surface chemistry on the detection sensitivity of IFA. IFA employing PEGylated GSH-QDs conjugates as labels demonstrated higher detection sensitivity than that rely on GSH-QDs conjugates. In addition, the presence of PEG layer facilitates the efficient loading and conjugation of antibodies to the surface of QDs without significant reduction in the optical properties of the fluorescent core usually described by our peers. ${ }^{46-48}$ This can also be attributed to the enhanced hydrophilicity and reduced steric hindrance caused by PEG, which prevent the nanoparticles aggregation in the antibody conjugation process and increase the stability of final conjugates. ${ }^{46,47}$ Moreover, the flexible PEG motif on the surface of nanoparticles could maintain the natural conformation of the antibody, ${ }^{47,48}$ and thus improve the affinity of the QD-antibody conjugates.
Through employing these rationally designed PEG/ GSH-QDs antibody conjugates in IFA, we were able to detect CRP levels ranging from 0.79 to $200 \mathrm{mg} / \mathrm{L}$. The test results can be checked with the naked eye under UV illumination for qualitative detection in emergence conditions, while quantitative results are able to be performed using an optical fiber spectroscopy. The spectra obtained from the test spot can be eventually analyzed for more differentials and can potentially be used for multiplexed detection using multicolor QDs. Interestingly, this dual mode of detection could support a wider range of emergency and central lab applications, and further indicates the rationality of our developed QD-based IFAs.

Compared with the previously reported QDs-based assay and traditional ELISA method, the advantages and disadvantages are briefly summarized in Table 1 . Even though the developed QD-based IFA test is not as sensitive as microplate and magnetic beads based assays, the sensitivity and dynamic range of this method provide satisfactory analytical characteristics for clinical CRP detection. Importantly, proposed QD-based assay has simpler and faster testing procedures, and requires less sample volume, which is more suitable for on-site testing in an emergency situation. The quantitative point-of-care testing kit may allow more accurate targeting of appropriate therapy and result in considerable cost saving.

\section{Conclusion}

A QDs-based IFA was successfully developed for rapid (within 5 minutes), sensitive, and quantitative detection of CRP in human serum using small sample volumes of $5 \mu \mathrm{L}$. Using surface PEGylation of QDs, the immunoassay performance of QDs-antibody conjugate was largely enhanced, and under optimal experimental conditions, the proposed QDs-based IFA was able to qualitatively detect concentrations as low as $0.19 \mathrm{mg} / \mathrm{L} \mathrm{CRP}$ in the serum sample. The detection range of this assay is $0.09-200 \mathrm{mg} / \mathrm{L}$ with a quantitative detection sensitivity of $0.79 \mathrm{mg} / \mathrm{L}$ using serum samples. Moreover, the obtained results were well correlated $(r=0.9805)$ with the data detected by a commercial latex 
agglutination assay, which confirms the potentiality of our QDs-based IFA for the development of rapid, quantitative point-of-care diagnostics.

\section{Acknowledgments}

This study was supported by funds from International Science \& Technology Cooperation Program of China (no 2014DFA33010), National Natural Science Foundation of China (81401754, 81172805 and 81571589), Shanghai STCSM Project (no 14ZR1413600 and no 11DZ1921805), Shanghai Municipal Health Bureau Research Grant (2013Y106), the Special Scientific Research Fund of Health Public Welfare Profession of China (201302018, 201202019), and Shanghai Rising-Star Program (14QA1404900). PF Zhang would like to acknowledge the helpful discussion with Professor Yitao Long from East China University of Science and Technology and financial support from Shanghai Upper Bio-Tech Pharma Co. Ltd.

\section{Disclosure}

The authors report no conflicts of interest in this work.

\section{References}

1. Pepys MB, Hirschfield GM. C-reactive protein: a critical update. J Clin Invest. 2003;111(12):1805-1812.

2. Clyne B, Olshaker JS. The C-reactive protein. JEmerg Med. 1999;17(6): 1019-1025.

3. Swardfager W, Herrmann N, Cornish S, et al. Exercise intervention and inflammatory markers in coronary artery disease: A meta-analysis. Am Heart J. 2012;163(4):666-676.e663.

4. Ridker PM, Hennekens CH, Buring JE, Rifai N. C-reactive protein and other markers of inflammation in the prediction of cardiovascular disease in women. New Engl J Med. 2000;342(12):836-843.

5. Libby P, Ridker PM, Maseri A. Inflammation and atherosclerosis. Circulation. 2002;105(9):1135-1143.

6. Labtestonline.org. Washington DC: American Association for Clinical Chemistry; hs-CRP [updated 2015 March 31; cited 2015 Sept 6]. Available from: https://labtestsonline.org/understanding/analytes/hscrp/ tab/test/. Accessed September 6, 2015.

7. Tsai HY, Hsu CF, Chiu IW, Fuh CB. Detection of C-reactive protein based on immunoassay using antibody-conjugated magnetic nanoparticles. Anal Chem. 2007;79(21):8416-8419.

8. Zhu X, Duan D, Publicover NG. Magnetic bead based assay for C-reactive protein using quantum-dot fluorescence labeling and immunoaffinity separation. Analyst. 2010;135(2):381-389.

9. Yang SF, Gao BZ, Tsai HY, Fuh CB. Detection of c-reactive protein based on a magnetic immunoassay by using functional magnetic and fluorescent nanoparticles in microplates. Analyst. 2014;139(21): 5576-5581.

10. Luo Y, Zhang B, Chen M, et al. Sensitive and rapid quantification of $\mathrm{C}$-reactive protein using quantum dot-labeled microplate immunoassay. J Transl Med. 2012;10(1):24.

11. Saha D, Roy D, Dhar TK. Immunofiltration assay for aflatoxin B1 based on the separation of pre-immune complexes. J Immunol Methods. 2013;392(1-2):24-28.

12. Andrews DM, Cubillos GF, Paulino SK, Seckinger DL, Kett DH. Prospective observational evaluation of the particle immunofiltration anti-platelet factor 4 rapid assay in MICU patients with thrombocytopenia. Crit Care. 2013;17(4):R143.
13. Ye Y, Zhou Y, Mo Z, et al. Rapid detection of aflatoxin B(1) on membrane by dot-immunogold filtration assay. Talanta. 2010;81(3):792-798.

14. Lucht A, Formenty P, Feldmann H, et al. Development of an immunofiltration-based antigen-detection assay for rapid diagnosis of ebola virus infection. J Infect Dis. 2007;196(Supplement 2):S184-S192.

15. von Lode P. Point-of-care immunotesting: approaching the analytical performance of central laboratory methods. Clin Biochem. 2005; 38(7):591-606.

16. Bravo D, Muñoz-Cobo B, Costa E, Clari MA, Tormo N, Navarro D. Evaluation of an immunofiltration assay that detects immunoglobulin $\mathrm{M}$ antibodies against the ZEBRA protein for the diagnosis of epsteinbarr virus infectious mononucleosis in immunocompetent patients. Clin Vaccine Immunol. 2009;16(6):885-888.

17. Uithoven KA, Schmidt JC, Ballman ME. Rapid identification of biological warfare agents using an instrument employing a light addressable potentiometric sensor and a flow-through immunofiltration-enzyme assay system. Biosens Bioelectron. 2000;14(10-11):761-770.

18. Fernández-Sánchez C, McNeil CJ, Rawson K, Nilsson O, Leung HY, Gnanapragasam V. One-step immunostrip test for the simultaneous detection of free and total prostate specific antigen in serum. J Immunol Methods. 2005;307(1-2):1-12.

19. Arlett JL, Myers EB, Roukes ML. Comparative advantages of mechanical biosensors. Nat Nanotechnol. 2011;6(4):203-215.

20. Xia X, Xu Y, Zhao X, Li Q. Lateral flow immunoassay using europium chelate-loaded silica nanoparticles as labels. Clin Chem. 2009;55(1): 179-182.

21. Posthuma-Trumpie GA, Korf J, van Amerongen A. Lateral flow (immuno)assay: its strengths, weaknesses, opportunities and threats. A literature survey. Anal Bioanal Chem. 2009;393(2):569-582.

22. Mao X, Wang W, Du TE. Dry-reagent nucleic acid biosensor based on blue dye doped latex beads and lateral flow strip. Talanta. 2013;114(0):248-253.

23. Liu C, Jia Q, Yang C, et al. Lateral flow immunochromatographic assay for sensitive pesticide detection by using $\mathrm{Fe} 3 \mathrm{O} 4$ nanoparticle aggregates as color reagents. Anal Chem. 2011;83(17):6778-6784.

24. Wang DB, Tian B, Zhang ZP, et al. Rapid detection of Bacillus anthracis spores using a super-paramagnetic lateral-flow immunological detectionsystem. Biosens Bioelectron. 2013;42:661-667.

25. Gogstad GO, Dale S, Brosstad F, et al. Assay of D-dimer based on immunofiltration and staining with gold colloids. Clin Chem. 1993; 39(10):2070-2076.

26. Parolo C, de la Escosura-Muñiz A, Polo E, Grazú V, de la Fuente JM, Merkoçi A. Design, preparation, and evaluation of a fixed-orientation antibody/gold-nanoparticle conjugate as an immunosensing label. ACS Appl Mater Inter. 2013;5(21):10753-10759.

27. Hong W, Huang L, Wang H, et al. Development of an up-converting phosphor technology-based 10-channel lateral flow assay for profiling antibodies against Yersinia pestis. J Microb Meth. 2010;83(2): $133-140$.

28. Corstjens PLAM, van Lieshout L, Zuiderwijk M, et al. Up-converting phosphor technology-based lateral flow assay for detection ofsSchistosoma circulating anodic antigen in serum. J Clin Microbiol. 2008;46(1):171-176.

29. Yang Q, Gong X, Song T, et al. Quantum dot-based immunochromatography test strip for rapid, quantitative and sensitive detection of alpha fetoprotein. Biosens Bioelectron. 2011;30(1):145-150.

30. Li Z, Wang Y, Wang J, Tang Z, Pounds JG, Lin Y. Rapid and sensitive detection of protein biomarker using a portable fluorescence biosensor based on quantum dots and a lateral flow test strip. Anal Chem. 2010;82(16):7008-7014.

31. Medintz IL, Uyeda HT, Goldman ER, Mattoussi H. Quantum dot bioconjugates for imaging, labelling and sensing. Nat Mater. 2005;4(6): 435-446.

32. Chan WCW, Nie S. Quantum dot bioconjugates for ultrasensitive nonisotopic detection. Science. 1998;281(5385):2016-2018.

33. Li DW, Qin LX, Li Y, Nia RP, Long YT, Chen HY. CdSe/ZnS quantum dot-cytochrome c bioconjugates for selective intracellular $\mathrm{O} 2^{\circ}$ - sensing. Chem Commun (Camb). 2011;47(30):8539-8541. 
34. Liu Y, Brandon R, Cate M, Peng X, Stony R, Johnson M. Detection of pathogens using luminescent $\mathrm{CdSe} / \mathrm{ZnS}$ dendron nanocrystals and a porous membrane immunofilter. Anal Chem. 2007;79(22): 8796-8802.

35. Wegner KD, Jin Z, Lindén S, Jennings TL, Hildebrandt N. Quantumdot-based förster resonance energy transfer immunoassay for sensitive clinical diagnostics of low-volume serum samples. ACS Nano. 2013; 7(8):7411-7419

36. Zhang H, Yee D, Wang C. Quantum dots for cancer diagnosis and therapy: biological and clinical perspectives. Nanomedicine. 2008;3(1): 83-91

37. Xie R, Kolb U, Li J, Basché T, Mews A. Synthesis and characterization of highly luminescent $\mathrm{CdSe}-$ Core $\mathrm{CdS} / \mathrm{Zn} 0.5 \mathrm{Cd} 0.5 \mathrm{~S} / \mathrm{ZnS}$ multishell nanocrystals. J Am Chem Soc. 2005;127(20):7480-7488.

38. Zhang B, Gong X, Hao L, Cheng J, Han Y, Chang J. A novel method to enhance quantum yield of silica-coated quantum dots for biodetection. Nanotechnology. 2008;19(46):465604.

39. Zhang P, Han H. Compact PEGylated polymer-caged quantum dots with improved stability. Colloid Surface A. 2012;402:72-79.

40. Zheng Y, Yang Z, Li Y, Ying JY. From glutathione capping to a crosslinked, phytochelatin-like coating of quantum dots. Adv Mater. 2008;20(18):3410-3415.

41. Ng RH, Brown BA, Valdes R. Three commercial methods for serum ferritin compared and the high-dose "hook effect" eliminated. Clin Chem. 1983;29(6):1109-1113.

42. Chaturvedi AK, Caporaso NE, Katki HA, et al. C-reactive protein and risk of lung cancer. J Clin Oncol. 2010;28(16):2719-2726.
43. Allin KH, Nordestgaard BG. Elevated C-reactive protein in the diagnosis, prognosis, and cause of cancer. Crit Rev Cl Lab Sci. 2011; 48(4):155-170.

44. Soman C, Giorgio T. Sensitive and multiplexed detection of proteomic antigens via quantum dot aggregation. Nanomedicine. 2009;5(4): 402-409.

45. Bentzen EL, Tomlinson ID, Mason J, et al. Surface modification to reduce nonspecific binding of quantum dots in live cell assays. Bioconj Chem. 2005;16(6):1488-1494.

46. Nagasaki Y, Kobayashi H, Katsuyama Y, Jomura T, Sakura T. Enhanced immunoresponse of antibody/mixed-PEG co-immobilized surface construction of high-performance immunomagnetic ELISA system. J Colloid Interf Sci. 2007;309(2):524-530.

47. Yoshimoto K, Nishio M, Sugasawa H, Nagasaki Y. Direct observation of adsorption-induced inactivation of antibody fragments surrounded by mixed-PEG layer on a gold surface. J Am Chem Soc. 2010; 132(23):7982-7989.

48. Yuan X, Yoshimoto K, Nagasaki Y. High-performance immunolatex possessing a mixed-PEG/Antibody coimmobilized surface: highly sensitive ferritin immunodiagnostics. Anal Chem. 2009;81(4):1549-1556.

49. Cheng X, Pu X, Jun P, Zhu X, Zhu D, Chen M. Rapid and quantitative detection of C-reactive protein using quantum dots and immunochromatographic test strips. Int J Nanomed. 2014;9(1):5619-5626.

50. Wu TL, Tsao KC, Chang C PY, Li CN, Sun CF, Wu JT. Development of ELISA on microplate for serum C-reactive protein and establishment of age-dependent normal reference range. Clin Chim Acta. 2002;322(1-2):163-168. 


\section{Supplementary materials}

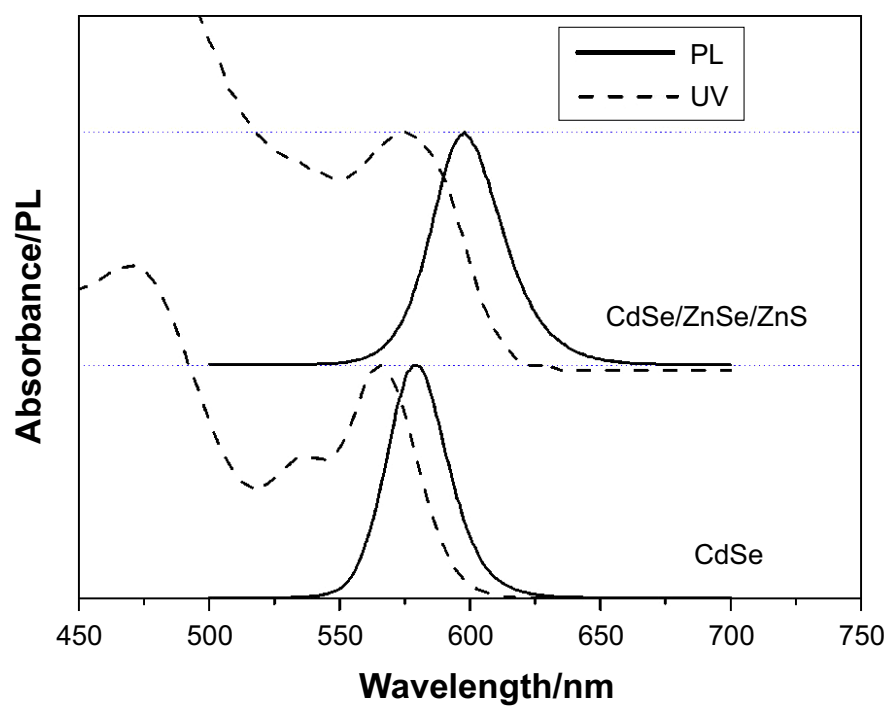

Figure SI UV-Vis absorbance and fluorescent spectra of CdSe core and CdSe/ZnSe/ZnS core/shell/shell QDs. Abbreviations: UV, ultraviolet; UV-Vis, ultraviolet-visible; PL, photoluminescence; QDs, quantum dots.
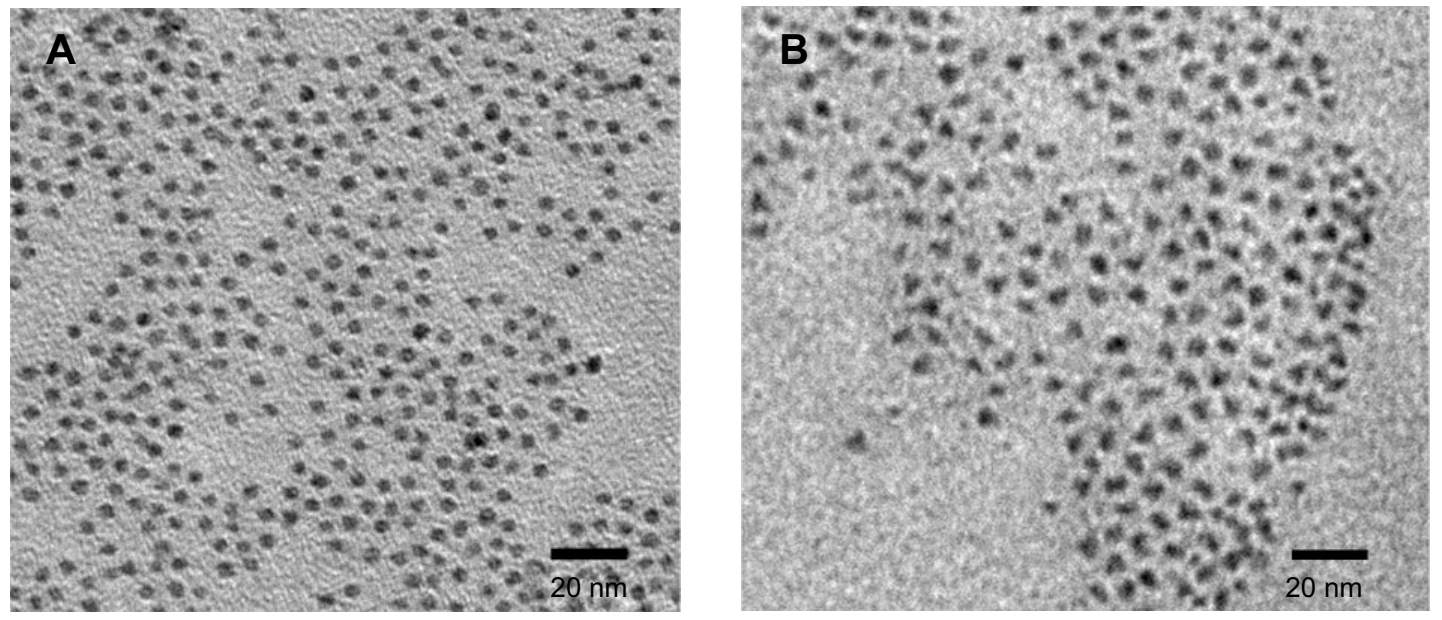

Figure S2 TEM graphs of CdSe core (A) and CdSe/ZnSe/ZnS core/shell/shell (B) QDs.

Abbreviations: TEM, transmission electron microscopy; QDs, quantum dots.

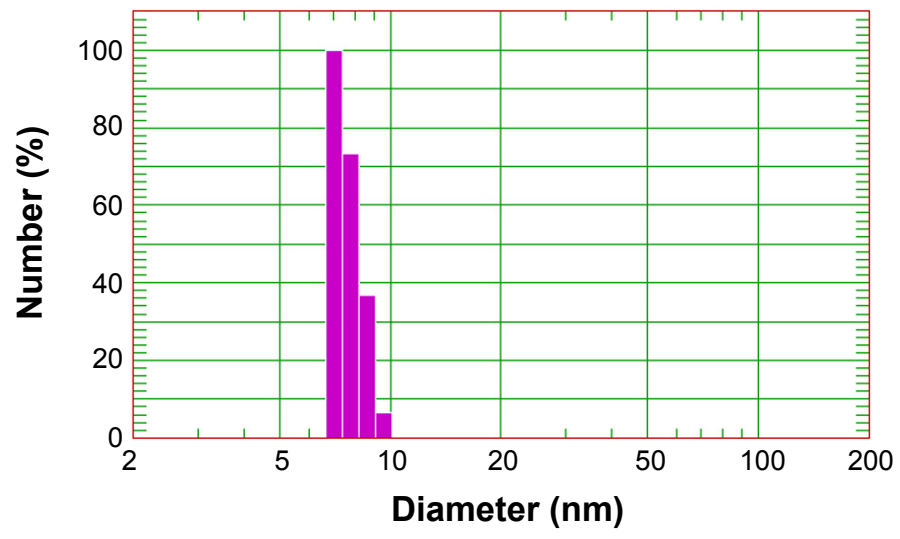

Figure S3 Dynamic light scattering analysis of GSH-QDs. Abbreviations: QDs, quantum dots; GSH, glutathione. 


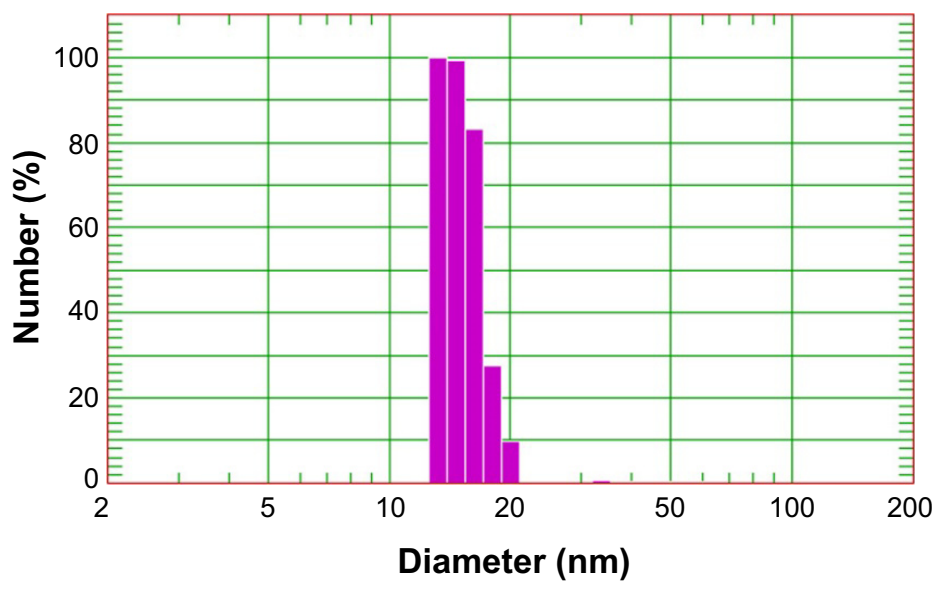

Figure S4 Dynamic light scattering analysis of PEG/GSH-QDs.

Abbreviations: QDs, quantum dots; GSH, glutathione; PEG, polyethylene glycol.

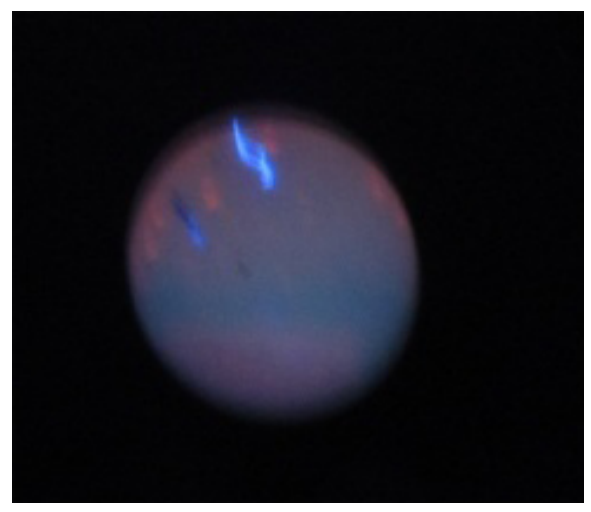

GSH-QDs

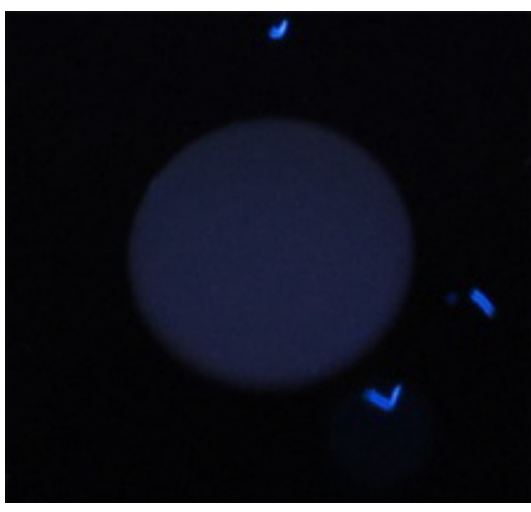

PEG/GSH-QDs

Figure S5 Comparison of non-specific binding of GSH-QDs and PEG/GSH-QDs conjugates with NC membrane without capturing antibody. Abbreviations: QD, quantum dot; GSH, glutathione; PEG, polyethylene glycol; NC, nitrocellulose.

\section{Publish your work in this journal}

The International Journal of Nanomedicine is an international, peerreviewed journal focusing on the application of nanotechnology in diagnostics, therapeutics, and drug delivery systems throughou the biomedical field. This journal is indexed on PubMed Central, MedLine, CAS, SciSearch $®$, Current Contents $\AA /$ Clinical Medicine,
Journal Citation Reports/Science Edition, EMBase, Scopus and the Elsevier Bibliographic databases. The manuscript management system is completely online and includes a very quick and fair peer-review system, which is all easy to use. Visit http://www.dovepress.com/ testimonials.php to read real quotes from published authors.

\footnotetext{
Submit your manuscript here: http://www.dovepress.com/international-journal-of-nanomedicine-journal
} 